\title{
ARTE LIXO MAR: UMA POÉTICA DE SENSIBILIZAÇÃO SOBRE O LIXO MARINHO
}

\author{
Maria Emanuele Bastos Fernandes ${ }^{1}$ \\ Deisi Beatriz Barcik ${ }^{2}$ \\ Allan Paul Krelling ${ }^{3}$
}

Resumo $O$ presente artigo tem como fator inicial a sensibilização sobre a problemática do lixo marinho e considera a Educação Ambiental como uma prática transversal, utilizou-se ainda, como poética e como ferramenta de Educação Ambiental, a construção e a exposição de esculturas feitas com lixo marinho. As esculturas produzidas entre outubro de 2018 e junho de 2019 foram expostas na cidade de Paranaguá (PR), em quatro ocasiões e lugares distintos do ano de 2019. Uma coleta de relatos e impressões sobre as exposições identificou o potencial de sensibilização dos visitantes sobre a problemática do lixo marinho, contribuindo para a promoção da Educação Ambiental não-formal. Cerca de 151 relatos foram analisados e concluiu-se que a exposição gerou sensibilização sobre o tema.

Palavras-chave: Lixo Marinho; Arte; Sensibilização; Educação Ambiental.

Abstract: In order to raise awareness about the problem of marine debris, and considering environmental education as a cross-cutting practice, the present work used, as poetics and as an environmental education tool, the construction and exhibition of sculptures made with marine waste. The sculptures produced between October 2018 and June 2019 were exhibited in the city of Paranaguá (PR, Brazil), on four occasions and different places during 2019. A collection of reports and impressions about the exhibitions identified the potential for sensitizing visitors about the problem of marine litter, contributing to the promotion of non-formal environmental education. About 151 reports were analyzed and it was identified that the exhibition was effective in generating awareness on the marine debris issue.

Keywords: Marine Debris; Art; Environmental Awareness; Environmental Education.

\footnotetext{
1 Universidade Federal do Paraná. E-mail: mariaemanuelebf@gmail.com.

2 Universidade Federal do Paraná. E-mail: beatrizbarcik@gmail.com.

3 Instituto Federal do Paraná. E-mail: allankrelling@hotmail.com
} 


\section{Introdução}

Historicamente, os mares e oceanos sempre tiveram grande importância para os humanos, tanto como fonte de recursos, como meio de locomoção, lazer e sobretudo na dinâmica ecológica. Os oceanos têm ainda um papel fundamental no controle do clima, produção de oxigênio e equilíbrio ecossistêmico. Porém, tal importância parece ser deixada em segundo plano em prol de uma produção mais barata e menos consciente, por parte das grandes indústrias e do consumo desenfreado. Com isso, observa-se um processo de redução na qualidade ambiental, inclusive de ecossistemas marinhos, especialmente pelo número crescente de problemas, já descritos na literatura, causados pelo lixo marinho.

O lixo marinho é um problema global, relacionado ao descarte incorreto de resíduos sólidos que, intencionalmente ou acidentalmente, chegam ao ambiente marinho por diversos meios. Tal problema está atrelado principalmente à falta de consciência de boa parte da população, pois muitos não sabem ou ignoram as consequências prejudiciais do descarte inadequado de resíduos como, a poluição de praias, a contaminação de animais usados como alimento e, consequentemente, a nossa contaminação. Tendo isso em mente, o ponto de partida dessa pesquisa foi o uso da arte como meio para a sensibilização ambiental acerca da problemática do lixo marinho, sendo a arte, neste caso, uma forma de Educação Ambiental não-formal. Essa abordagem se justifica pelo entendimento de que a busca pela satisfação de certas indagações humanas, apenas através de exposições científicas, não sensibiliza as pessoas necessariamente. Ou seja, expor um problema não é suficiente. Logo, é importante estimular conexões mais profundas com as problemáticas ambientais e a arte pode ser uma ferramenta interessante, no que diz respeito às reflexões sobre o lixo marinho. A questão que se coloca é: exposições artísticas sensibilizariam e permitiriam a demonstração de sentimentos e reflexões por parte das pessoas, em relação à problemática apresentada?

O presente artigo tem o objetivo de demonstrar a utilização da arte na busca por sensibilizar as pessoas, avaliando-se, assim, se a arte pode provocar certos sentimentos e ter efeito sobre as formas de ver o lixo marinho. Para isso, assim como outros artistas que já se valeram de práticas semelhantes, utilizou-se uma poética própria e o lixo marinho como recurso para a construção de esculturas e posteriores exposições.

\section{Lixo marinho e seus impactos}

Segundo o texto orientador da IV Conferência Nacional do Meio Ambiente (2013, p. 33), conceitua-se lixo marinho como sendo "qualquer tipo de resíduo sólido produzido pelo homem gerado em terra ou no mar que, intencionalmente ou não, tenha sido introduzido no ambiente marinho, incluindo o transporte destes materiais por meio de rios, drenagens, sistemas de esgoto ou vento". Sobre o lixo marinho, Juliana Nucci $(2010$, p.1) comenta: 
O lixo marinho provém de ações antropogênicas e afeta diretamente o ambiente marinho. Resíduos plásticos aparecem como a maior ameaça a este ecossistema, uma vez que são os mais abundantes tanto em peso, como em quantidade. Ainda assim, o despejo desses resíduos nos oceanos é cada vez maior.

Tais ações antropogênicas se caracterizam por todo e qualquer derivado de atividades feitas ou produzidas por humanos, em termos gerais, 0 lixo propriamente dito. Aproximando as teorias de Fagundes e Missio (2019, p.2399) e Nucci (2010), o crescimento de tais ações e a má gestão dos resíduos sólidos causam impactos significativos à fauna marinha que, involuntariamente, entra em contato com o lixo; uma vez que os detritos são transportados por correntes marinhas e se instalam em zonas de biodiversidade causando grandes danos para diversas espécies.

O texto orientador da IV Conferência Nacional do Meio Ambiente (CNMA, 2013, p. 34) informa que, há algumas décadas, existem "esforços para prevenir e reduzir o lixo marinho", no entanto, as evidências indicam que o problema não apenas persiste como cresce continuamente: ainda em 2013, os estudos calcularam que os oceanos recebiam aproximadamente 14 bilhões de toneladas de lixo anualmente.

Com uma enorme capacidade de dispersão, em razão do movimento natural das ondas, das correntes marinhas e dos ventos, o lixo marinho pode ser encontrado nas áreas mais remotas do globo, no meio dos oceanos ou ilhas isoladas, flutuando sobre a água, submerso, ou mesmo nas regiões sobre as áreas costeiras. Distância esta que parece favorecer o teimoso e ultrapassado pensamento de que longe dos olhos o problema não existe. Contudo, o documento da CNMA de 2013 já informava que "uma vez no mar, a retirada e a destinação adequadas tornam-se muito mais complicadas" (CNMA, 2013, p. 34). E ainda que:

Esses resíduos, em sua maioria, são compostos por materiais sintéticos, com destaque para os plásticos que apresentam alta resistência e durabilidade, podendo fragmentar-se e permanecer por longos períodos no ambiente. Também são constantemente encontrados no mar metais, vidros, resíduos de pesca e de embarcações, materiais de construção, isopor, borracha, corda, têxteis, madeira e materiais perigosos, tais como resíduos hospitalares e nucleares. Uma vez nos ambientes marinhos e costeiros, aqueles resíduos causam danos significativos aos animais. Seja por enredamento, ingestão de plásticos por invertebrados, peixes, aves, tartarugas e mamíferos marinhos ou pela introdução de espécies exóticas transportadas pelo lixo flutuante. Também são comuns os prejuízos econômicos e estéticos causados às atividades humanas.

Revbea, São Paulo, V. 16, № 2: 191-211, 2021.

Revista brasileira educação ambiental 
Garreta-Harkot et al. (2010) afirmavam que os impactos do lixo marinho no meio ambiente resultam em problemas das mais diversas ordens, entre eles: o prejuízo à pesca e à navegação, a alteração e deterioramento das paisagens costeiras e marinhas e o agravamento de situações relacionadas à saúde pública, como a contaminação da água e a disseminação de doenças, fatos que afetam diretamente a qualidade de vida, o cotidiano das populações litorâneas e o turismo. A preocupação com a degradação estética também é comentada por Cinquetti (2004, p.315): "A disposição inadequada de lixo em vias públicas, rios e outros locais impróprios pode ocasionar degradações estéticas (poluição visual)". Esses problemas demandam maior investimento público municipal, pois há uma preocupação das prefeituras em manter uma estética agradável principalmente nas praias. A questão é que esses investimentos normalmente são feitos no final do processo, ou seja, atuando no final da geração dos resíduos, quando na verdade deveriam ser aplicados em ações realizadas no início da cadeia.

Apesar de o lixo marinho ter como principais portas de entrada as "cidades costeiras" (CNMA, 2013, p.34), os impactos e danos decorrentes dos resíduos não são só estéticos, tampouco ficam presos nas áreas em que ocorrem os descartes. Embora haja a hipótese de restrição a esses locais de descarte, isso não quer dizer que o problema possa ser ignorado, visto que os danos se espalham por todos os oceanos e zonas costeiras. Assim, hipoteticamente restritos ou de fato espalhados, contaminando todo o ecossistema marinho, é possível supor que uma das principais causas do problema do lixo marinho é a falta de consciência de grande parte da população mundial, pois ainda existe o pensamento de que os mares e oceanos têm amplitude e profundidade suficiente para receber nossos rejeitos. Segundo Araújo e Costa (2003, p. 64), há uma crença de que esses ambientes possuem capacidade para aguentar o descarte de todo tipo de resíduo sólido e efluentes sem sofrer consequências ambientais.

Nos dias atuais podemos observar o uso indiscriminado de descartáveis como padrão de ação, tal como é descrito por Araújo e Costa (2003, p.64). Esse fato revela uma sociedade global na qual a praticidade da vida corriqueira, cada vez mais, acarreta o consumo de materiais sintéticos, principalmente derivados do petróleo como plásticos, nylon e o isopor. Esses materiais, vistos em garrafas e embalagens, por exemplo, possuem características de durabilidade, resistência e, principalmente, baixo custo para a cadeia de produção e distribuição de produtos embalados ou envasados características essas vistas como positivas pela indústria, mas que têm resultados opostos para o meio ambiente - de qualquer modo, seu uso ainda é prioritário em relação a outros compostos como o vidro ou materiais biodegradáveis (NUCCl, 2010, p.29). Ainda que haja certa parcela da população preocupada com a sustentabilidade, a postura de grande parte das indústrias colabora para que o consumo de materiais potencialmente poluidores não seja reduzido, pois frequentemente as opções para 0 
consumidor mudar seus hábitos são raras. Ou seja, parece que faltam ofertas alternativas, basta uma ida aos supermercados para constatar tal informação.

Todo esse consumo de materiais sintéticos e de baixo custo, movido pela sociedade capitalista em prol da redução de despesas de produção e consequente aumento de lucro, sobretudo pela descartabilidade dos objetos, segundo Araújo e Costa (2003, p.64) pode sobrelevar o custo ambiental. Assim, tal como enfatiza Cardoso (2010, p.1337), é passada a hora de refletir sobre a quantidade de lixo produzido e sobre as formas como ele é encarado, discutido e descartado:

Nesse contexto de crítica ao consumismo em prol de um desenvolvimento sustentável, os produtos deveriam passar a se vincular ao duradouro, devendo também contribuir para a desaceleração dos ciclos de substituição, evitando-se o descartável.

Para que parte do problema do lixo seja minimizado, é necessário que muitas mudanças aconteçam, entre elas destacam-se: a atuação no início do ciclo de consumo com a escolha de materiais sustentáveis e, sobretudo, a conscientização da população sobre suas alternativas e usos. Em relação à conscientização sobre o consumo, vale lembrar que a Educação Ambiental, inclusive na forma como os recursos naturais e industriais são utilizados, está incluída. Desse modo, a Educação Ambiental se configura como importante estratégia de contenção nos ciclos de substituição e descarte e consequente diminuição do lixo, pois ela age justamente na prevenção do problema.

\section{Educação Ambiental}

A Educação Ambiental é uma ferramenta importante na orientação e conscientização humana "para um mundo limpo e sustentável", é importante "educar para preservar e com isso contribuir para mudanças de atitudes e adoção de práticas ambientalmente corretas" (DIAS FILHO; CAVALCANTI, 2011, p. 55). Para Reigota (1994, p. 15), a Educação Ambiental não deve ser resumida apenas à preocupação com "os aspectos biológicos da vida", mas deve ser uma educação política, que considera as relações "econômicas, sociais e culturais entre a humanidade e natureza". A Educação Ambiental política é, então:

questionadora das certezas absolutas e dogmáticas; é criativa pois busca desenvolver metodologias e temáticas que possibilitem descobertas e vivências, é inovadora quando relaciona os conteúdos e as temáticas ambientais com a vida cotidiana e estimula o diálogo de conhecimentos científicos (REIGOTA, 1994, p. 15). 
Os aspectos culturais e sociais falam sobre o perfil e cotidiano das pessoas e a Educação Ambiental pode ser pensada levando isso em conta. Em relação ao lixo marinho, segundo estudos feitos por Dias Filho e Cavalcanti (2011, p. 55), o perfil dos usuários de praias influencia o modo como estes entendem o lixo marinho e como se relacionam com o meio ambiente. Comerciantes, banhistas, surfistas, pescadores, turistas percebem a praia, 0 mar e a poluição de modo diverso. Esses mesmos autores comentam que as "Campanhas de Educação Ambiental devem ser realizadas de maneira diferenciada para cada perfil de usuário", pois cada grupo tem cotidiano e aspectos culturais próprios, não podendo ser aplicada a mesma metodologia para todos com a mesma eficácia.

No Brasil, a Educação Ambiental tem como característica principal a transversalidade, ou seja, deve estar presente em todos os âmbitos da educação formal e não formal. o Artigo $2^{\circ}$ da Lei Federal ํㅜ 9795, de 27 de abril de 1999, prevê que: "A Educação Ambiental é um componente essencial e permanente da educação nacional, devendo estar presente, de forma articulada, em todos os níveis e modalidades do processo educativo, em caráter formal e não-formal'. Além disso, o Inciso III do Artigo 4ํ da mesma Lei prevê que um dos princípios básicos da Educação Ambiental é "o pluralismo de ideias e concepções pedagógicas, na perspectiva da inter, multi e transdisciplinaridade" (BRASIL, 1999, Art. $4^{\circ}$ ).

A transversalidade na educação pode ser entendida como aquela que considera os conhecimentos científicos, mas não ignora os conhecimentos empíricos. Reigota (1994, p.42) recorrendo às definições de Félix Guattari explica: a transversalidade "não desconsidera a importância de nenhum conhecimento, mas rompe com a ideia de que os conhecimentos sejam disciplinares e que são válidos apenas os conhecimentos científicos." Nesse sentido, a Educação Ambiental não é responsabilidade apenas da área biológica e do ambiente escolar, mas, como dito, ela deve ser pensada em todas as esferas que envolvem o ser humano, considerando, sobretudo, a relação entre a humanidade e a natureza. A natureza humana é rica e a Educação Ambiental ganha ao considerar outros aspectos que compõem a essência humana além da razão. Marin (2006, p. 278) comenta que a Educação Ambiental não pode considerar apenas a cientificidade e a transmissão do conhecimento científico, pois, de modo geral, "educar

pressupõe trabalhar com as sensibilidades, afetividades, capacidades imagética e criadora e, ao fazê-lo, despertar para a verdadeira essência ética do ser humano". Daí a importância de considerar a arte também como um instrumento de sensibilização e educação para as questões ambientais.

\section{Arte e sensibilização}

Jorge Coli (2006, p.107) escreve que a razão faz parte do objeto artístico, mas que, inevitavelmente, "a obra enfeixa elementos que escapam ao domínio do racional e sua comunicação conosco se faz por outros canais: da 
emoção, do espanto, da intuição, das associações, das evocações, das seduções". E como uma função da arte, destaca o sentido de "aprendizagem", salientando que essa aprendizagem não é do domínio do racional ou do dizível apenas, mas também da sensibilidade:

(...) domínio sem fronteiras nítidas, muito diferente do mundo da ciência, da lógica, da teoria. Domínio fecundo, pois nosso contato com a arte nos transforma. Porque o objeto artístico traz em si, habilmente organizados, os meios de despertar em nós, em nossas emoções e razões, reações culturalmente ricas que aguçam os instrumentos dos quais nos servimos para apreender o mundo que nos rodeia (COLI, 2006, p.111).

Atualmente, fazer conexões artísticas e criativas com o mundo que nos cerca não tem sido tarefa simples, uma vez que, tal como afirma Voltolini e Moralles (2007, p. 5) "existe uma fragmentação no pensar e no agir", principalmente no que diz respeito à forma como a educação formal transmite o conhecimento sem, muitas vezes, abrir espaço para a expressão da criatividade e dos sentimentos. Nesse sentido, pode-se interpretar que existe a necessidade do uso de métodos mais humanísticos para que assim aconteça a sensibilização ambiental, não de maneira segmentada, mas integrada. Do mesmo modo, Fávero (2007, p.1126) também comenta que a utilização e discussão de processos artísticos em espaços incomuns podem trazer questões mais profundas da vida contemporânea, as quais ultrapassam os resultados estéticos do estado da arte.

\section{História da arte e processo artístico: breve revisão}

Segundo Coli (2006), Marcel Duchamp (1990-1930) com seus ready made, na década de 1910, abria as portas para a provocação e incorporava à arte novos materiais. A partir daquele momento, o óleo sobre tela ou a escultura em mármore ou em bronze ganharam a companhia de materiais bem menos nobres, além de alterar o modo como a arte era vista, tanto pelos artistas como pelo público.

Kurt Schwitters (1887-1948), poeta, pintor e escultor alemão, também utilizou materiais fora dos ditos comuns em suas obras Merz, compostas essencialmente de pequenos pedaços do cotidiano: recortes de jornais, bilhetes de ônibus, entre outros materiais que encontrava nas ruas de Hanôver (GOMBRICH, 1999, p. 600). De acordo com Octavio Paz (2002, p.57) a palavra Merz teria o significado derivado de Ausrmerzen (resíduos), Schmerz (pena) e Herz (coração). Segundo Strickland e Boswell (2009, p. 156), a substituição do óleo sobre tela por esses materiais teria, para Schwitters, o sentido ou o propósito de se distinguir do "mundo pretensioso, satisfeito consigo mesmo", e se configurava como uma crítica à sociedade da produção e do descarte. 
O polonês naturalizado brasileiro, Frans Krajcberg (1921-2017) desde 1978 questionava e criticava a interferência antrópica negativa, mais especificamente no ambiente natural do Brasil. Sua arte tinha como característica a utilização de "resíduos da destruição": cipós, troncos, raízes queimadas e palmeiras ressecada. Para Oliveira (2015) a forma que Krajcberg propõe sua poética, questionando os sentidos da arte e promovendo 0 humanismo ecológico, o torna um "educador ambiental" preocupado em promover reflexões.

Outro artista que trabalha com materiais descartados é Vik Muniz. Partindo do desconforto e da preocupação com o uso desordenado de descartáveis causado pelo consumo de nossa sociedade e as consequências sociais que o envolvem, Vik Muniz, em parceria com uma comunidade de catadores no Rio de Janeiro, traz questões sobre o lixo. Segundo Stumpp e Minuzzi (2011), o documentário Lixo extraordinário (1999), também produzido por ele, mostra o cenário onde Muniz acompanha a vida e os desafios das pessoas que vivem e trabalham no lixão. $O$ artista se apropria dos resíduos urbanos e cria montagens gigantes de obras conhecidas na História da Arte, como Marat, de Jacques Louis-David e Narciso, de Caravaggio, personificando estas obras com o rosto e relacionando-as com a história de vida de alguns catadores presentes no documentário.

Um artista contemporâneo muito significativo na utilização do lixo, mais especificamente do lixo marinho como material para sua poética e sensibilização, é o mexicano Alejandro Durán. Em suas obras podemos ver as conexões que ele faz com o ambiente, intercalando resíduos plásticos em paisagens naturais das praias da América Central.

Ele usa detritos internacionais para criar esculturas baseadas em cores específicas do local que fundem a mão do homem com a natureza. Às vezes, ele distribui os objetos da mesma maneira que as ondas; outras vezes, o plástico imita algas, raízes, rios ou frutas, refletindo a infiltração de plásticos no ambiente natural (WASHED UP).

Todos esses artistas, com exceção de Duchamp, têm algo em comum: a crítica sobre como a sociedade utiliza os recursos e a problemática do descarte, o que torna possível supor alguma consciência ambiental e social e o desejo de, com a interpretação do mundo e o fazer artístico, também conscientizar. Vale lembrar que o uso do lixo e outros materiais ditos não artísticos, também foi e ainda é utilizado por muitos artistas, entre outros, Renata de Andrade, Jota de Azevedo, Bordalo II. não que necessariamente haja alguma preocupação ambiental, propriamente dita, por parte de todos os artistas que utilizam tais materiais. 
A abordagem do lixo como matéria bruta e como poética, seja pela ótica ambiental, social ou colaborando com a estética de alguns artistas, no campo das Artes Visuais, não é nova, pelo contrário, data do início do século $X X$ e demonstra, de uma ou outra maneira, que o uso do lixo traz questões para além da pura materialidade, o uso também toca as pessoas, o que muitas vezes é, pode ou deveria ser um dos propósitos da arte em nossa época.

Comprometido com a questão ambiental, o presente artigo tenta trazer o posicionamento crítico em relação à sociedade, tal como Schwitters e Durán, com enfoque no lixo marinho como material e como poética para a prática artística e como uma problemática a ser refletida criticamente e repensada. Nesse sentido, Arte Lixo Mar teve - como obra e exposições - e tem - com a divulgação do trabalho nesse artigo - como princípio conscientizar sobre os problemas do lixo marinho.

\section{Arte Lixo Mar}

A poética e as exposições Arte Lixo Mar, fizeram uso do método de pesquisa qualitativa que, de acordo com Brantes (2013, p.603-607) se caracteriza por buscar a coleta de dados abertos, como imagens e textos que enfatizam "o aprofundamento da análise e o exercício da imaginação", mas fazendo com que a pesquisa "volte-se ao sensível", mais especificamente, no que diz respeito à pesquisa em artes.

O fazer artístico, ou seja, a criação da obra, é um ato singular da ou do artista onde ela ou ele prolonga seu corpo e mente por meio do material, manifestando reflexões e conexões que só ela ou ele poderia fazer. Ainda que o fazer artístico seja singular e subjetivo, vale ressaltar que, tal como afirmam Costa e Silva (2015, p. 9 -10) "a produção artística vincula-se a contextos objetivos, questões históricas, sociais e conceituais", e ainda que o conhecimento artístico não seja totalmente ou somente científico, ele é capaz de "ampliar as percepções de mundo".

\section{Seleção e produção de materiais}

Para a construção das esculturas foi utilizado o lixo marinho coletado em outros estudos realizados no Laboratório de Conservação e Manejo do Campus Paranaguá do IFPR e, no presente artigo, foi atribuído o termo de reúso para esses materiais. Os materiais usados em cada escultura ${ }^{4}$ possuem alguma relação com os problemas que suscitam, uma vez que procuram

\footnotetext{
${ }^{4}$ A produção da artista Umanuvem resultou em oito esculturas que foram expostas anexadas de placas descritivas, informando os tipos de resíduos utilizados e uma frase de reflexão, tal como segue pormenorizado nos tópicos seguintes.
} 
evidenciar a origem e/ou a consequência desses materiais inseridos no ambiente marinho.

A seleção de materiais se deu em duas fases: na primeira, pelo tipo de composição do material, tais como isopor, madeira e plásticos em geral. $\mathrm{Na}$ segunda fase, aconteceu a separação dos resíduos pela sua cor de origem: branco, azul, preto, verde, vermelho, amarelo e marrom. A seleção e separação desses objetos facilitou o processo de composição de determinadas esculturas, tal como Ecologia do plástico (2019) e Metamorfose do micro (2019) pois havia a preocupação em compor objetos artísticos harmoniosos tal como explicitado a seguir (Figura 1).
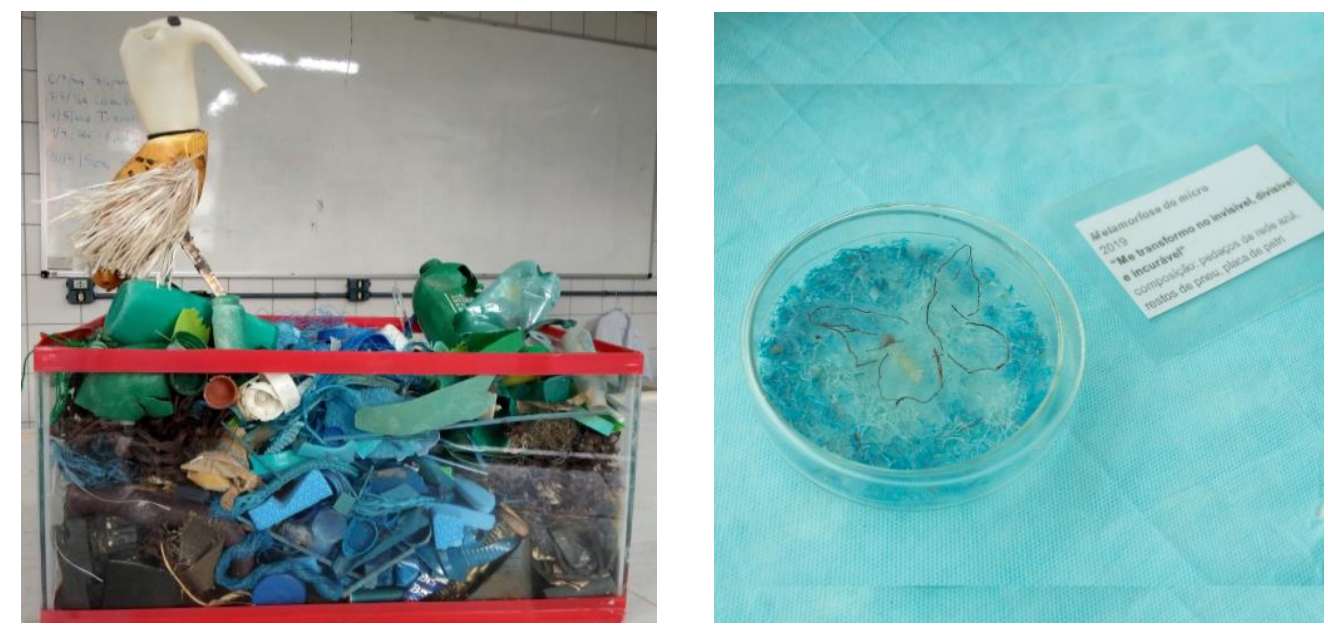

Figura 1: A. Foto Escultura Ecologia do plástico. B. Metamorfose do micro. Fonte: Autor.

\section{Produção das esculturas e Reflexões: relatos da artista}

Sereia dos mares: a sociedade em que vivemos está repleta de mitos e lendas derivados de vários lugares do mundo, a sereia é um desses mitos que sofreram e sofrem modificações pelo imaginário coletivo. Porém, de certa forma, ainda mantém sua essência: uma criatura metade mulher, metade peixe. Foi essa ideia que inspirou a composição da escultura Sereia dos mares (2019, Figura 2A). Algo intuitivo relacionado ao mar e às marés, e sobre o lixo, o uso das redes e cordas de pesca que são deixados no mar ou nas areias das praias e até mesmo os acessórios, geralmente ligados ao feminino, que foram e podem, com certa frequência, ser encontrados nas praias. Pode ser comum imaginarmos a sereia como um ser belo e encantador, por isso a frase: "A fantasia dos mares é real", mas nessa escultura o objetivo era mostrar 0 desconforto do emaranhado das redes que compõem o corpo da sereia na escultura. Alguns detalhes como a "costela" exposta em seu tronco e as tampas de garrafas de champagne cortadas indicam uma forma mais sombria (embora não tenha sido o principal objetivo) de como o resíduo pode se mostrar como algo inicialmente belo e sedutor. 
Castelo de Areia: foram utilizadas garrafas do tipo pet de diversos tamanhos que, agrupadas, formam diferentes níveis de altura (Figura 2B). Pensando em como seria o resultado e na mensagem que seria transmitida, foram selecionados brinquedos encontrados durante a etapa de separação, para fazer a relação com objetos que foram deixados na praia. Em relação à placa informativa o uso da frase "O que restará para nossas crianças brincarem?" busca transmitir uma ideia de que o futuro, do modo como vivemos hoje, pode não ser tão promissor quanto pensamos e o quanto nossas atitudes podem afetar outras gerações.

Canoa revirada: nas primeiras fases do processo criativo, enquanto os resíduos eram separados por composição, uma das alternativas encontradas foi imaginar as suas respectivas trajetórias. A primeira reflexão que ocorreu durante essa prática foi: como esses pedaços de madeira teriam chegado (ou sido deixados) ao mar? A ideia então foi ir agrupando esses materiais buscando o formato de canoa no intuito de mostrar como as partes separadas podiam se transformar em uma só, mas isso sem alterar de modo permanente as formas originais, ou melhor, tentando manter as formas tais como foram encontradas (Figura 2C). A escolha em representar uma pessoa exercendo a atividade de pesca tenta inserir o ser humano como parte principal do problema do lixo, busca, também, problematizar como estão sendo feitas as pescas predatórias e industriais, lançando, e muitas vezes abandonando, as redes ao mar. A frase que acompanhava a escultura dizia: "Sim! o lixo pode se rebelar, assim como o mar".
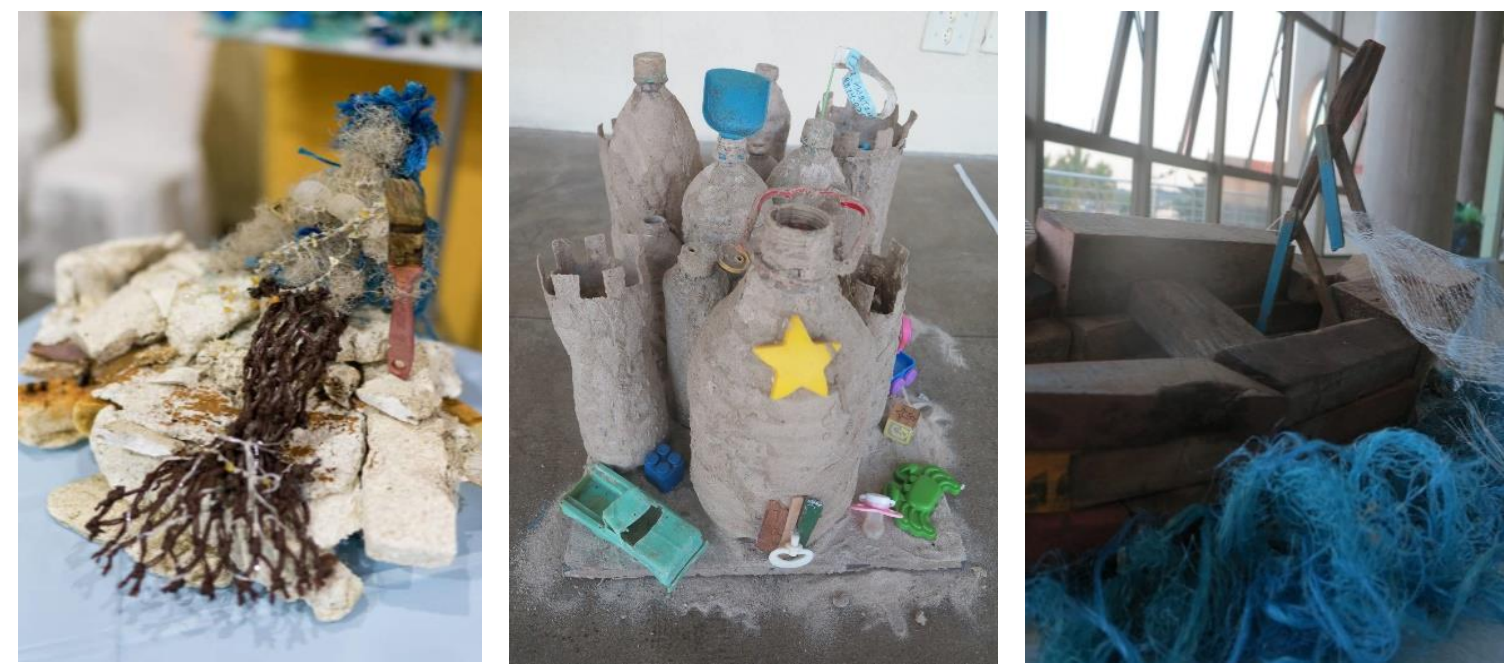

Figura 2: A. Sereia dos mares; B. "Castelo de Areia"; C. Canoa revirada. Fonte: Autor.

Água-morta: uma das consequências do lixo marinho é a morte de animais por ingestão de resíduos como o plástico. Na escultura Água-morta o foco não esteve somente nos resíduos e em suas composições, mas também nos animais que morrem, muitas vezes, vítimas dos sacos e das sacolas plásticas - um símbolo autêntico do consumo - e do descaso humano (Figura 
3A). Água-morta quer também representar a morte dos animais marinhos. A frase que acompanhou a escultura dizia: "Não só a água-viva é tóxica, mas a água morta também".

Ecologia do plástico: desde o início do projeto, houve a pretensão em produzir algo com sentido biológico do assunto em questão, ou seja, tratar os modos como o plástico afeta a fauna de modo geral, bem como seus ecossistemas. A ideia de utilizar um aquário é uma metáfora para sistemas ecológicos únicos, que possuem sua própria dinâmica. Houve interesse em demonstrar como seria se houvesse uma Ecologia do plástico própria (Figura $1 \mathrm{~A})$ de maneira que impactasse o espectador pela aproximação com o problema de tamanha interferência no ambiente natural e que, hipoteticamente, um novo sistema estaria surgindo, onde o plástico, que é o resíduo mais recorrente pela sua não degradação, é o protagonista deste novo mundo formado por restos.

Desca(n)so: certo dia estava passeando em uma praia na cidade de Matinhos (PR). Em um momento, sentada na areia olhando para o mar, vi ao meu lado crianças brincando com garrafas pet. As crianças faziam castelos de areia enquanto seus pais descansavam na cadeira de praia com diversos acessórios e embalagens. Contudo, o que parecia ser apenas uma típica cena familiar me levou a refletir o quão impactante é um simples passeio pela praia: quantas embalagens de picolés, garrafas pet e até roupas de banho são deixadas por lá? Com esse pensamento, procurei utilizar resíduos que, em sua maioria, penso serem partes de um contexto - de um grande descaso na forma e no cenário de um simples descanso - onde esses resíduos poderiam ter sido deixados. A proporção entre a representação dos objetos que compõem o cenário da obra não está de acordo com os objetos reais, pois esta não era uma preocupação, o objetivo era trabalhar com os resíduos encontrados que parecem fora de contexto, mas estão muito relacionados com a praia, como o tecido usado na elaboração do guarda sol da composição que, originalmente, era uma roupa de banho. Isso mostra o quanto é fácil encontrar resíduos nas praias, às vezes trazidos de outra localidade pelo oceano e às vezes descartados ali mesmo pelos banhistas, que deveriam refletir sobre seu $\operatorname{Desca}(n)$ so: "Essa garrafinha não fará diferença?".

Metamorfose do micro: Metamorfose é uma palavra que liga os dois estados de uma transformação. A ideia se conecta muito ao significado do título da escultura (Figura 1B): a real transformação do lixo marinho e como isso pode literalmente refletir na vida como um todo $A$ maneira que escolhi representar a transformação foi na forma de uma borboleta, justamente para que o espectador pudesse fazer essa conexão, e, junto à leitura da placa - "Me transformo no invisível, divisível e incurável" - consiga entender que o lixo marinho não é só o que podemos ver em grande escala, mas que há o micro que nos afeta de fora para dentro, com a contaminação dos mares e dos peixes e por conseguinte a contaminação de nossos organismos através da ingestão de animais marinhos que acabaram por ingerir plásticos contaminantes etc.

Revbea, São Paulo, V. 16, № 2: 191-211, 2021. 
O tempo e a quantidade: este talvez seja o trabalho que tem a abordagem mais filosófica sobre o tema dessa poética. O tempo e a quantidade (Figura $3 \mathrm{C}$ ) são trazidos através da ampulheta, no intuito de problematizar a subdivisão do plástico que, no decorrer do tempo vai se transformando em microplástico, mas não desaparece. A ampulheta foi a forma encontrada para representar a quantidade exacerbada de resíduos que produzimos e o tempo que eles permanecerão na natureza A placa tenta provocar através de um jogo de palavras: "o tempo que passa e a quantidade que ultrapassa", fazendo a relação que não nos resta muito tempo para reversão dessa triste realidade.
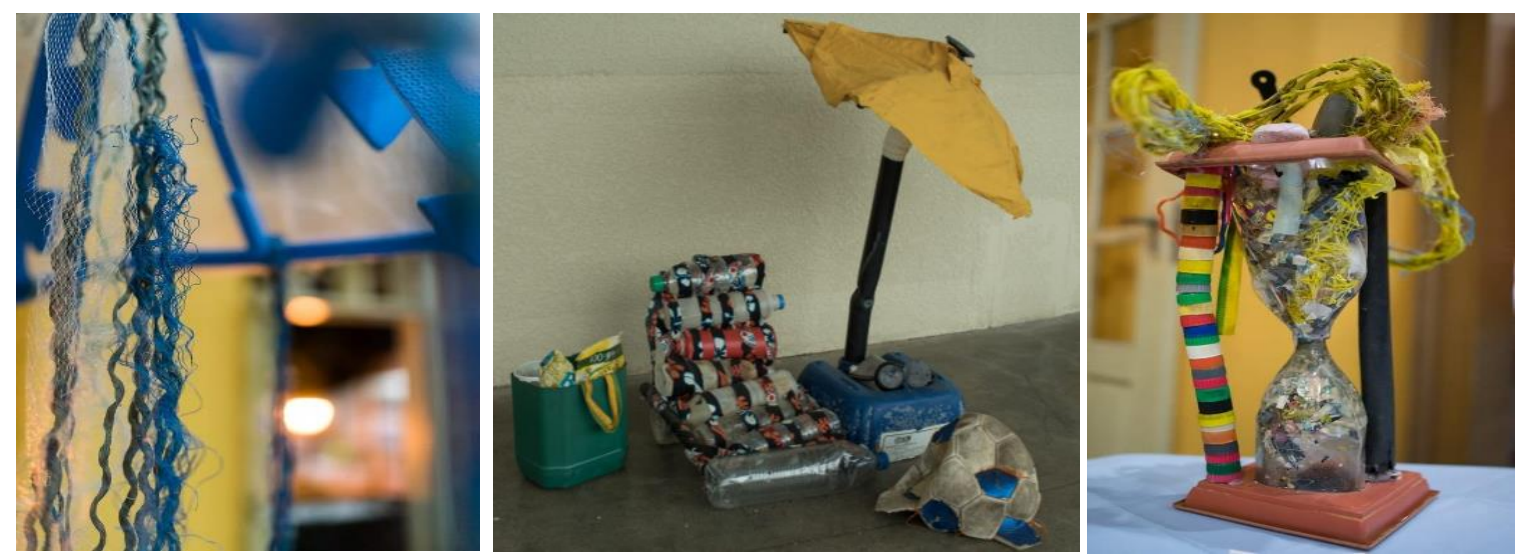

Figura 3: A. Água-Morta; B. Desca(n)so; C. O tempo e a quantidade". Fonte: Autor.

\section{Exposição}

Após a produção das esculturas, foi preciso pensar nas exposições, em como cada um dos trabalhos estaria disposto nos lugares em que seriam expostos, visto que cada espaço teria suas peculiaridades e desafios. Foram estabelecidos contatos prévios com os responsáveis pelos eventos e locais onde seria possível que os trabalhos fossem expostos. O único critério para escolha dos espaços, além, é claro, do aceite das instituições e da necessidade óbvia de presença de um público, foi a possibilidade de trabalhar com a educação não formal.

Sobre as exposições, havia o anseio e a suposição de que, através das experiências visuais com as esculturas, os espectadores seriam impactados de alguma forma, por consequência, poderia dar início a algumas reflexões sobre a problemática do lixo marinho, suas causas e consequências. A divulgação das exposições aconteceu através de um cartaz virtual informando os locais e as datas (Figuras 4A e 4B). Este cartaz circulou pelas redes sociais como Facebook, WhatsApp e Instagram. O cartaz tinha como objetivo instigar a curiosidade a partir do título "ARTE LIXO MAR" mostrando apenas uma das obras para situar o leitor(a) do que ele(a) poderia encontrar na exposição, e informar os locais e datas para visitação. 

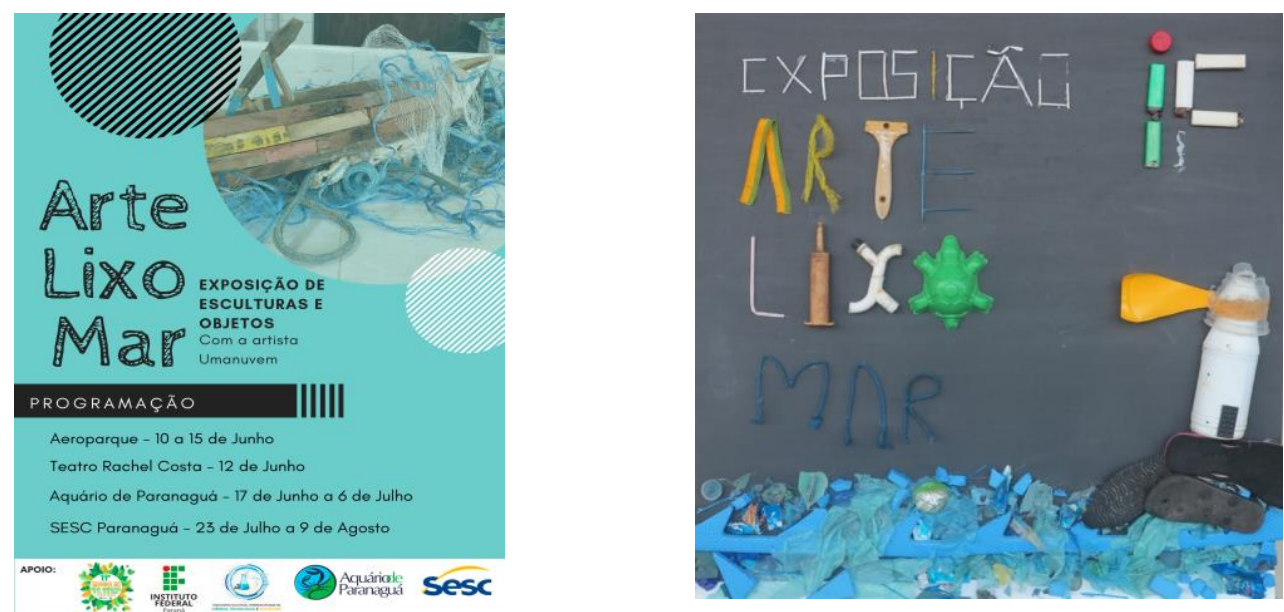

Figura 4: Material de divulgação das exposições. A. Cartaz de divulgação físico e digital. B. Banner para localização da exposição. Fonte: Autor.

Para a avaliar se as esculturas alcançaram seu objetivo principal, foi deixado um caderno para anotações com a seguinte pergunta: "Qual ou quais sentimentos a exposição causou em você?". Dessa maneira, os espectadores poderiam descrever em palavras os sentimentos que tiveram ao visitar a exposição, estando, assim, de acordo com o método qualitativo. As esculturas foram expostas em quatro lugares distintos, conforme o cartaz de divulgação e a tabela abaixo:

Tabela 1: Tabela de relação lugares e datas das exposições.

\begin{tabular}{cccc}
\hline Local & Evento & Duração & N$^{\circ}$ de respostas \\
\hline $\begin{array}{c}\text { Aeroparque de } \\
\text { Paranaguá }\end{array}$ & $\begin{array}{c}14^{\circ} \text { Semana Municipal do } \\
\text { Meio Ambiente }\end{array}$ & 7 dias $(10 / 06 / 2019-15 / 06 / 2019)$ & 44 \\
\hline $\begin{array}{c}\text { Teatro Rachel } \\
\text { Costa }\end{array}$ & $\begin{array}{c}\text { Evento Nacional } \\
\text { Interdisciplinar em Ciência } \\
\text { Tecnologia e Sociedade } \\
\text { (ENICTS) }\end{array}$ & 5 horas (12/06/2019-12/06/2019) & 9 \\
\hline $\begin{array}{c}\text { Aquário de } \\
\text { Paranaguá }\end{array}$ & Não houve evento & 20 dias (17/06/2019-06/07/2019) & 93 \\
\hline $\begin{array}{c}\text { SESC - } \\
\text { Paranaguá }\end{array}$ & Não houve evento & 18 dias (23/07/2019-09/08/2019) & 5 \\
\hline
\end{tabular}

Fonte: Autor 


\section{Resultados e Discussão}

Como visto anteriormente, existe um referencial histórico artístico que traz informações sobre a utilização de materiais incomuns, como o lixo, empregados por artistas desde o século XX. Artistas como Schwitters, Krajcberg, Durán, entre outros, se valeram dessa abordagem, em linhas gerais, para criticar ou para despertar a consciência quanto aos impactos do consumo e descarte da sociedade. Nesse mesmo sentido, mas relacionando-se diretamente com a Educação Ambiental, Scamati e Lima (2017, p. 44) observaram que o uso de resíduos para criar arte (scrapbooking) funcionou como ferramenta pedagógica para a formação do indivíduo "ecológico". Da mesma forma, o presente trabalho compactua com os resultados dos autores, reforçando a importância da disponibilidade dos mais variados recursos da e na educação a fim de romper paradigmas e promover a reflexão acerca dos temas apresentados (SCAMATI; LIMA, 2017, p.52-53).

Não só os usos de materiais incomuns constituem a crítica pretendida, mas também a forma como foram organizados e apresentados, onde os materiais expõem valores simbólicos mais profundos para a artista. Esses valores simbólicos podem ser entendidos como a compreensão da nocividade da matéria prima utilizada, bem como a sua apropriação, acúmulo e reorganização, transformando o lixo marinho, então, em peças de arte com o intuito de sensibilizar o público justamente em relação aos problemas relacionados ao lixo marinho. Conforme Fávero (2007) observou, olhar o lixo como "objeto de desejo transformador" possibilita a busca de novos significados e reflexões sobre ele. Ou como bem explicava Ostrower (1977, p.187) sobre "As potencialidades e os processos criativos" não se limitarem ao campo das Artes [nem aos materiais comumente utilizados], mas que elas estariam presentes nas mais diversas áreas do conhecimento humano. Um grande exemplo de tal afirmação é observado no trabalho de Barros e Layoun (2018, p.33), onde há o uso das aulas de arte para a valorização da paisagem regional do Mato Grosso do Sul, bem como a Educação Ambiental com foco em reutilização e redução de resíduos " $A$ arte feita com materiais alternativos aproveita o 'lixo' de uma sociedade de consumo, [...] essa sucata entra como material de pesquisa, de colagem, de construção, dando origem a objetos construtivos e expressivos" que, ampliando a discussão, possuem potencial sensibilizador sobre problemas que envolvem a vida humana e o meio ambiente.

Logo, pode-se afirmar que as conexões ambientais e artísticas, envolvidas no processo de criação das esculturas e exposições, são resultados do grande interesse em sensibilizar para as questões ambientais. Ainda nesse sentido, ao considerar os relatos deixados nas exposições, os resultados obtidos pelo presente trabalho reforçam o pensamento observado na literatura nacional (SCAMATI; LIMA, 2017, p. 52-53; BARROS; LAYOUN, 2018, p.33) e apontam para uma efetiva sensibilização. Pois, partindo do ponto observado por Coli (1997), onde a sensibilidade do ser humano se faz como um instrumento essencial para a aprendizagem, pode-se também supor que as 
esculturas possuem potencial para sensibilizar e contribuir de modo positivo e significativo no processo de ensino-aprendizagem, mesmo que de modo indireto, pois, com base nos relatos, as esculturas foram capazes de provocar sensações, sentimentos e reflexões.

Admiração e indignação, pois pude perceber que são resíduos que poderiam ser aproveitados ou reciclados, mas percebo que estavam jogados no mar. Mas parabenizo todos que fazem a limpeza desses resíduos e que reaproveitam nesta exposição! (Comentário deixado por um visitante no caderno da exposição no Aquário de Paranaguá)

Muito Bacana a ideia de transformar o lixo em arte, ainda mais esses resíduos do mar para que sejam destinados corretamente! A sensação que causa é de impotência e vergonha, por saber que, quem deveria preservar, está destruindo, mas também, esperança! Por saber que ainda existe pessoas que se preocupam com uma questão tão séria! Parabéns." (Comentário deixado por um visitante no caderno da exposição no Aeroparque)

Contudo, não é possível afirmar categoricamente que todas as pessoas que visitaram as exposições puderam aprender algo com ela, nem mesmo é possível dizer que as obras foram capazes de sensibilizar efetivamente o público (apesar da potencialidade existente). Pois a sensibilização, ou mesmo o aprendizado de algo, exigiria que os espectadores olhassem as esculturas, mas também prestassem atenção às placas e assim fizessem uma relação entre os fatos (poluição, lixo marinho) a frase e a obra. Essa relação entre submeter-se a uma atividade reflexiva focada no tema (lixo marinho) e a sensibilização do indivíduo, em longo prazo, é um tema frequentemente questionado. Buscou-se avançar na compreensão desse aspecto, ao avaliar os relatos dos participantes.

De forma similar, Wyles et al. (2017, p. 530) compararam a influência que a participação em limpezas de praia (mutirões) tem sobre seus participantes em relação com outras propostas como uma caminhada ou atividades voltadas a conhecer espécies locais. Os autores observaram que a limpeza de praia foi bastante significativa para cada participante, tendo sido indicada, inclusive, como a que mais os sensibilizou. Da mesma forma, podese esperar que uma pessoa que visite uma exposição de arte que utilizou resíduos sólidos retirados do mar e que abordou a problemática do lixo marinho, no futuro, considerando o valor educativo da exposição, traga benefícios ambientais como a participação ativa desse indivíduo que, porventura, ampliou sua consciência de responsabilidade individual e coletiva sobre o meio ambiente.

Os relatos deixados nas exposições podem ter sofrido algum 
direcionamento, se for considerada a relação dos espaços expositivos com questões pertinentes ao meio ambiente. Essa inferência se baseia em padrões observados anteriormente na literatura. Por exemplo, Wyles et al. (2013, p.107) observaram que a visita a um aquário, a passeio, aumenta significativamente atitudes e intenções a ter uma atitude pro-ambiental. Visto que, uma das exposições se realizou no Aquário de Paranaguá (PR) e que este foi o local de exposições com maior quantidade de relatos, pode-se considerar que o mesmo padrão observado no Reino Unido também se observou nesse trabalho. Outro exemplo, foi a exposição realizada no Aeroparque (Paranaguá, PR), onde estava acontecendo um evento de cunho ambiental com várias atividades. Esse resultado se assemelha aquele encontrado por Silva e Krelling (2019) em pesquisa sobre a percepção dos visitantes de uma coleção didática sobre lixo marinho. Os autores identificaram que os alunos do curso Técnico em Meio Ambiente possuem percepção diferenciada sobre a capacidade de sensibilização da coleção, especialmente sobre conhecimento técnico acerca do tema, associando essa diferença ao contato prévio destes estudantes com conceitos de educação.

Nas respostas coletadas no Aquário de Paranaguá (PR), nota-se que algumas demonstram uma divergência no que foi solicitado com a pergunta ou fizeram relação com o lugar utilizado para exposição. Como por exemplo, os comentários: "20 pila é sacanagem"; "Tiraram os pinguins, não gostei!"; "Eu gostaria de peixes da Coreia do Sul"; e 30 comentários políticos: "FORA BOLSONARO - NEM PENSAR!"; e ainda demonstrações de descontentamento geral em relação ao espaço e, talvez, em relação à exposição: "Fiquei triste muito caro pra pouca atração, sem criatividade, não souberam o que fazer com recurso muito ruim, $R \$ 5,00$ reais tava bem pago."

Santos (2019, p. 26), em relação à sua pesquisa sobre a Educação Ambiental e as ações antrópicas no ambiente marinho, informa que os indivíduos tendem a manter o pensamento fechado, quanto às questões relacionadas ao desenvolvimento socioambiental já que muitas vezes, no caso de sua pesquisa, os respondentes "não se colocaram no problema, e apontaram o problema do lixo e seu descarte apenas responsabilizando outras pessoas [...] não percebem a relação que existe entre a produção de lixo e 0 consumismo gerado por uma sociedade capitalista".

Embora a afirmação de Santos (2019) também possa ser observada em alguns comentários da ARTE LIXO MAR, a preocupação com a problemática do lixo ainda se mostrou existente, provocando os mais diversos sentimentos, como indignação em relação ao comportamento humano - "Fiquei impressionada $\mathrm{cl}$ a quantidade de lixo encontrada no mar, a falta de consciência do ser humano". E "Vontade de matar o ser humano", comentários, deixados no caderno de relatos no Aeroparque em Paranaguá (PR) preocupação com a postura política em relação à problemática - como no comentário deixado no Aquário de Paranaguá (PR): "FALTA PLANO DO GOVERNO PARA INCENTIVO À RECICLAGEM!!!" - Além de expressões de sentimentos em relação a problemática e cumprimentos pela iniciativa da

Revista brasileira educação ambiental 
artista - como o comentário deixado no caderno de relatos na exposição no Aquário de Paranaguá (PR): "Medo, e decepção por saber que vivemos próximos a tantas pessoas que não cuidam do nosso meio ambiente. Parabéns pela iniciativa".

Observou-se, através da análise de frequência de palavras citadas nos 151 comentários deixados, que sentimentos como tristeza, revolta e indignação foram predominantes. Por outro lado, menções de parabenização pelo trabalho e a necessidade de cuidados com o mar, a natureza e o ambiente também apareceram. O sentimento negativo dominante, acompanhado de alguns sentimentos positivos reitera àqueles observados por outras estudos usando formas alternativas de abordar a Educação Ambiental não formal. Silva e Krelling (2019) observaram que os dois principais sentimentos dos visitantes de uma exposição didática sobre lixo marinho foram "revolta" e "tristeza", porém sentimentos positivos como "esperança" também foram indicados.

Reigota (1994) comenta que existe uma necessidade na Educação Ambiental em relação a como as áreas do conhecimento em geral dialogam, e que muitas vezes dificulta a transversalidade prevista em lei. Por isso, é importante reconhecer que embora certos resultados, percebidos nos relatos, não se mostrem promissores, muitos outros espectadores relatam muito mais do que foi solicitado, demonstrando algum nível de conscientização. Esses resultados indicam grande semelhança com a literatura (WYLES, 2013, SCAMATI; LIMA, 2017, BARROS; LAYOUN 2018, WYLES, 2018, SILVA; KRELLING, 2019), reforçando a ideia de que a arte pode ser uma ferramenta complementar àquelas utilizadas para a Educação Ambiental aplicada à temática do lixo marinho.

Diante das respostas à questão, notou-se que o objetivo inicial da proposta foi atendido: os conhecimentos sobre a problemática do lixo marinho foram abordados e interpretados de maneira poética e artística pela autora e artista Umanuvem, como visto nas esculturas - que utilizaram lixo marinho como recurso, meio e poética - e nas descrições reflexivas de cada uma delas, bem como em todo o percurso da pesquisa. Em contrapartida, pode-se perceber, ao analisar os relatos, o posicionamento receptivo e reflexivo de boa parte do público visitante.

\section{Conclusões}

O lixo marinho é um problema global, que exige soluções muito mais complexas do que apenas Educação Ambiental, pois ele afeta a biota, a flora, contamina mares e praias. No entanto, ao contrário das medidas remediadoras, a Educação Ambiental é eficiente no sentido da prevenção do problema. Todavia, dificilmente resultados diretos e imediatos serão mostrados, como a diminuição de descartáveis. Por isso, é importante que cada vez mais os problemas sejam evidenciados das mais diversas formas, sinalizando não só que ainda existem, mas mais importante, que algo deve ser feito para impedir o seu crescimento. 
A abordagem visual das exposições, considerando a Educação Ambiental pelo prisma da transversalidade, parece ter possibilitado a reflexão e o desenvolvimento de sentimentos concretos nos espectadores, como a preocupação com a responsabilidade sobre o lixo marinho, o que pode caracterizar o início de um processo de Educação Ambiental. Os resultados desse trabalho estão em consonância com trabalhos anteriores, reforçando o papel da arte para a Educação Ambiental voltada à problemática do lixo marinho. E embora o conteúdo deste artigo não relate o caso de uma prática exclusiva dos ambientes formais de educação, os resultados obtidos através dos relatos deixados pelos visitantes das exposições, em boa parte, se mostraram positivos e significativos em relação à Educação Ambiental nãoformal. Assim, utilizando como ferramenta a Educação Ambiental não-formal, pode-se contribuir principalmente em pesquisas onde 0 foco seja a sensibilização e não o modelo padrão de aprendizado, sendo Barros e Layoun (2018), Favero (2007), Marin (2007) e muitos outros, exemplos desses diálogos. Uma vez que, o ser humano precisa de sentimentos e emoções para se conectar com o mundo e com os outros seres ou, nesse caso, entender a importância de um problema, a utilização de empreitadas como essa pode se mostrar como prática positiva para a sensibilização sobre a problemática do lixo marinho.

Contudo, e embora os resultados tenham se mostrado positivos para esta pesquisa e possam colaborar com pesquisas e desenvolvimento de poéticas futuras, não é possível concluir que todos os espectadores chegaram ou chegarão ao objetivo de serem sensibilizados sobre o problema do lixo marinho através da arte, justamente porque a arte, como uma forma de conhecer e se relacionar com o mundo, tem a característica de ser aberta e disponível para quaisquer interpretações.

\section{Referências}

ARAÚJO, M. C. B; COSTA, M. F. Lixo no ambiente marinho. Ciência Hoje. V. 32 n. 191, p. 64-67, mar, 2003.

BARROS, A. G.; LAYOUN, B. R. Arte regional de Mato Grosso do Sul: a Educação Ambiental e as aulas de arte. Revista Brasileira De Educação Ambiental (RevBEA), v.13, n.3, pp.26-41.

BRANTES, H. R. S. Busca por uma Metodologia de pesquisa em poéticas visuais. In: VI Seminário Nacional de Pesquisa em Arte e Cultura Visual Goiânia-GO: UFG, FAV. Anais eletrônicos. P.602-611, 2013. Disponível em: $<$ https://files.cercomp.ufg.br/weby/up/778/o/2013-077eixo2 H\%C3\%A9lio Renato Silva Brantes.pdf>. Acesso em: 02.out.2019.

BRASIL. Decreto-lei no 9.795, de 27 de abril de 1999. Dispõe sobre a Educação Ambiental, institui a Política Nacional de Educação Ambiental e dá outras providências. Casa Civil. Disponível em <http://www.planalto.gov.br/ccivil 03/leis/l9795.htm>. Acesso em: 15.nov.2020. 
CARDOSO, J. Arte e sustentabilidade: uma reflexão acerca dos problemas ambientais. Anais do Encontro da Associação Nacional de Pesquisadores em Artes Plásticas "Entre Territórios": 19ª ed., 2010 Cachoeira. Bahia. set, 2010. P. 1336-1347.

CINQUETTI, H. S. LIXO, resíduos sólidos e reciclagem: uma análise comparativa de recursos didáticos. revista Educar, Curitiba, n. 23, p. 307-333, 2004. Editora UFPR.

COLI, J. O que é Arte. 15. ed. São Paulo: Editora Brasiliense, 1995. 131 p.

CONFERÊNCIA NACIONAL DO MEIO AMBIENTE, 4르, 2013, Brasília. Vamos Cuidar do Brasil: 4ª Conferência Nacional do Meio Ambiente: Resíduos Sólidos. Texto Orientador. Brasília, 2013, $2^{a}$ ed., 48 p. Disponível em: $<$ https://www.mma.gov.br/images/arquivo/80054/Livreto CNMA textoorientador-FINAL.pdf>. Acesso em: 02. out.2019.

COSTA, R. X.; SILVA, M. B. Investigação e/sobre artes visuais: artista/pesquisador/professor. Anais do Encontro Nacional da Associação Nacional de Pesquisadores de Artes Plásticas. "Compartilhamentos na arte: redes e conexões". 24a ed., 2015. Santa Maria/RS. set, 2015. p. 3450 - 3465.

DIAS FILHO, M. F. et al. Avaliação da percepção Pública na contaminação por lixo marinho de acordo com o perfil do usuário: estudo de caso em uma praia urbana no nordeste do Brasil. Revista da Gestão Costeira Integrada. vol. 11, num. 1, 2011, pp. 49-55.

FAGUNDES, L. M.; MISSIO, E. Resíduos plásticos nos oceanos: ameaças à fauna marinha. Revista online: Brazilian journal of development. pg. 23962401. v.5. mar. 2019. Curitiba.

FAVERO, S. M. C., Rastros e restos: relato de uma experiência. Anais do Encontro Nacional da Associação Nacional de Pesquisadores de Artes Plásticas "Dinâmicas Epistemológicas em Artes Visuais": 16aํ ed., 2007 Florianópolis. Santa Catarina. set, 2007. P 1124-1132.

GARRETA-HARKOT, P. F. at al. Projeto lixo marinho: estratégias de ação para enfretamento no litoral brasileiro. Anais do Congresso Brasileiro de Oceanografia: 3ㄹed., 2010 Rio Grande. Rio Grande do Sul. mai, 2010. P. 12821286.

GOMBRICH, E. H. A história da Arte. Tradução de: Álvaro Cabral, G. E. N. 16. ed. Rio de Janeiro: LTC, 2012. Título original: The story of art.

MARIN, A. A. A educação nos caminhos da sensibilidade estética. Revista Inter Ação, v.31, n.2, 2007, p.277-290: Educação inclusiva.

NUCCI, J. M. R. Lixo marinho com enfoque em resíduos plásticos. 2010. $47 f$. TCC - Universidade Presbiteriana Mackenzie Centro De Ciências Biológicas e da Saúde Curso De Ciências Biológicas, São Paulo, 2010. 
OLIVEIRA, U.T. Frans Krajberg: história de vida e processo de criação. 2015. 181 f. Tese (Doutorado) - Curso de Educação, Centro de Educação, Universidade Federal do Espírito Santo, Vitória, 2015. Disponível em: $<$ http://portais4.ufes.br/posgrad/teses/tese 9281 UILIAN Tese corrigida 09.1 1.201520151119-211622.pdf >. Acesso em: 28. nov.2019.

OSTROWER, F. Criatividade e processos de criação: 21. ed. Rio de Janeiro. Editora Vozes. 1977.

REIGOTA, M. O que é Educação Ambiental: 2. Ed. São Paulo: Editora Brasiliense: 2012.

SANTOS, P. W. A Educação Ambiental repensando ações antrópicas no ambiente marinho: o caso do manguezal de Aracaju. 2019. 40 f. TCC (Graduação) - Curso de Ciências Biológicas, Universidade Federal de Sergipe, São Cristóvão, 2019.

SCAMANTI, R. L. B.; LIMA, L. D. S. C. Luxo do lixo: a arte Scrapbooking como ferramenta de Educação Ambiental. Revista Brasileira de Educação Ambiental, v.12, n.2, pp. 34-55, 2017.

RIBEIRO DA SILVA, H.; KRELLING, A. P. (). Marixo: desenvolvimento de uma coleção didática e científica referente a lixo marinho e análise de sua eficiência como ferramenta de Educação Ambiental. Revista Brasileira De Educação Ambiental, v.14, n.4, p.09-24. 2019.

STRICKLAND, C.; BOSWELL, J. Arte Comentada: da pré-história ao pósmoderno. 15. Ed. Rio de Janeiro: Nova Fronteira, 1999.

STUMPP, M.E.; MINUZZI, R. F. B. Pele Urbana: fronteiras possíveis. In: Encontro Nacional da Associação Nacional de Pesquisadores de Artes Plásticas Subjetividade, Utopias e Fabulações: 20aa ed., 2011 Rio de Janeiro. Anais. Rio de Janeiro. Anpap, 26 de set - 1 de out. 2011. P.4053-4063.

PAZ, Octavio. Marcel Duchamp ou o Castelo da Pureza. São Paulo: Editora Perspectiva S.A., 3를 edição, 2002/

VOLTOLINI, R. V.; MORALLES, A. G. M. AS DANÇAS CIRCULARES COMO INSTRUMENTO DE SENSIBILIZAÇÃO AMBIENTAL. Com Scientia, Curitiba, v. 3, n. 3, p. 2-17, jan. 2007.

WASHED UP. Alejandro Durán. Disponível em: <https://alejandroduran.com/>. Acesso em: 16. ago. 2019.

WYLES, K. J.; PAHL S.; HOLLAND M.; THOMPSON R. C. Can Beach Cleans Do More Than Clean-Up Litter? Comparing Beach Cleans to Other Coastal Activities. Article first published online: May 19, 2016; Issue published: June $1,017$.

WYLES, K. J.; PAHL S.; WHITE M., MORRIS S., CRACKNELL D., THOMPSON R. C. Towards a Marine Mindset: Visiting an Aquarium Can Improve Attitudes and Intentions Regarding Marine Sustainability, Visitor Studies, v.16, n.1, p.95-110, 2013.

Revista brasileira educação ambiental 